\title{
A Comparative Analysis Between Brand Attachment and Similar Constructs Like Brand Attitude
}

\author{
Ren Xinting, Shen Fangyi, Ji Xiaofen \\ School of Fashion, Zhejiang Sci-Tech University, Hangzhou, China \\ uniquejay@163.com, 345625393@qq.com
}

\begin{abstract}
This research conducts a comprehensive comparison between brand attachment and similar constructs, by which we confirm that brand attachment can be an independent construct from an indirect perspective. In the process of comparison, we found that these similar constructs representing different responses from consumers to brands exist a hierarchical relationship with different levels. Brand attachment is at the top of this hierarchy, which means it can predicts other consumer-brand responses, such as brand preference and brand commitment. We argue that the progression from brand involvement to brand attachment in this hierarchy is a reflection of consumer-brand relationship development.

Index Terms - brand attachment; brand involvement; brand attitude; brand preference; hierarchical relation
\end{abstract}

\section{I . Introduction}

Brand attachment is one of the hot topics about relationship marketing. But in China, the research seems just about to start and mainly limited into summary of foreign literature. We can't fully take advantage of this new construct in marketing region until we have a profound knowledge about it. As a result, this research is no exception but summary of foreign literature. Furthermore, we hope that we can draw some insightful conclusion through our research. Attachment theory is originated from psychology and result from Bowbly's pioneering working. Since lacking of articulated relationship framework, the research about relationship marketing had ever been stagnated(Fournier,1988). In 1989, American marketing scholar Susan E Schultz finished her doctorial dissertation "An empirical investigation of person-material possession attachment", which marked that attachment theory was introduced to consumer behavior region formally. Consequently, brand attachment can be used to describe the relationship between consumers and brands. In other words, brand attachment has conceptualized and specified the relationship, which provides a viable way for future research.

Brand attachment can be viewed as a relationship per se between consumers and brands as well as a reaction from consumers to brands. Besides brand attachment, researchers have identified other reactions to brands, such as brand involvement, brand attitude, brand satisfaction, brand trust, brand preference, brand commitment, brand loyalty and brand love. Although general consensus has been reached about brand attachment in academia, there is still a query: whether brand attachment is just a similar construct of other wellestablished constructs, such as brand love. In this research, we will give a clarified comparison to ensure that brand attachment can stand out from other similar constructs.
Interestingly, we find that these similar constructs exists a hierarchical relation, in which brand attachment is on the top.

\section{II . Constructs comparison}

This research has covered a wide range of similar constructs, including brand involvement, brand attitude, brand satisfaction, brand trust, brand preference, brand commitment, brand loyalty and brand love.

\section{A. Attachment VS Attitude}

\section{1) Brand-self connection}

Attitude can be regarded as evaluation to an object, which can refer to a person, a thought or a product here. Positive attitude can result from that if brand-related benefits exceed consumers' expectation. In other words, brand attitude can be a pure objective assessment to a brand. As a result, one person holds a positive attitude to a brand, which does not necessarily mean that this person connects the brand with his/her own selfconcept. By contrast, brand-self connectedness is the core of brand attachment.

\section{2) Related-behavior}

Consumers' attachment to brand suggest explicit behavior outputs, such as proximity maintenance and separation distress. In order to maintain the relationship with attachment figure, an individual can voluntarily invest his/her own available resources, such as time, energy and money. By contrast, positive attitude doesn't necessarily suggest explicit behavior outputs. According to dual-attitude theory, people can hold opposite attitudes simultaneously. In fact, the relation between attitude and behavior is not just only dependent on attitudinal attributes but also on a series of contingent factors. In general, brand attachment shows more accurate prediction to consumers' behavior than favorable brand attitude.

\section{3) Effects and causes}

What we have reflects and defines what we are or our identity, which is a basic truth in consumer behavior region. When an individual gradually emerges with an object and incorporates it into his/her own concept, the object is helping the individual maintain his/her identity. That is to say, attachment reflects the compatibility between consumers' own concept and brand philosophy. Hence, the formation of brand attachment is mainly based on consumers' own perception. Compared with attachment, attitude is usually formed through peripheral way, especially consumers' involvement to the product category is low. Peripheral way means that consumers' 
attitude towards specific brand is based on others' opinion and situational cues.

\section{B. Attachment VS Involvement}

\section{1) Brand-self connection}

In most definitions, involvement has reflected the product-self relatedness. According to different motives, Park and Young proposed two involvement styles: cognitive involvement and affectional involvement. While cognitive involvement emphasizes on physical or functional advantages that consumers benefit from, affectional involvement emphasizes on psychological or emotional resonance that consumers can arouse. As we see, involvement does not guarantee the merger between brand and self-concept, which means consumers can only rely on functional benefit with less emotional arousal.

\section{2) Related-behavior}

The same products in different situations can cause different levels of involvement, which means that involvement is subject to situational cues. By contrast, despite of situational enticement and incentives, consumers can still attach to brands in the strong emotional bond or connectedness.

\section{Brand VS Commitment}

\section{1) Temporal orientation}

Commitment expresses the willingness that consumers will maintain the relationship with brands. In most definitions, commitment is labeled as psychological pledge to future behavior. By comparison, attachment reflect an extant relationship between consumers and brands. In most definitions, attachment is labeled as a mental status with brands, which means automatic extractions of brand-related information.

\section{2) Related-behavior}

According to different motives, commitment can also be classified as two categories: affective commitment and calculative commitment. Affective commitment is based on consumers' emotional attachment and resonance containing consumers' willingness to maintain the relationship with brands. Calculative commitment is seemingly loyalty but indeed opportunistic. Specifically, consumers will continue to buy the same brands as long as switch cost outweighs the current benefit they get. As discussed above, commitment means a psychological pledge, however, this pledge can have nothing to do with affection. Consumers' commitment to brand may due to lack of stong competitors or be constrained by contracts.

Brand commitment derived form brand attachment can be reflected by explicit behavior, such as brand loyalty, forgiveness to brands' mishap, positive word-of-mouth. By contrast, calculative commitment will probably not forgive brands' mishap as easy as affective commitment. Conversely, consumers' commitment to brand isn't sufficient enough to induce emotional attachment, because motives behind commitment leave unspecified yet.

\section{Attachment VS Preference}

\section{1) Brand-self connection}

Brand preference reflects the importance of brands' specific attributes to consumers. These attributes may refer to be functional or affectional. When consumers show specific brand preference, it is not necessary to incorporate brand into self-concept for consumers. According to extant literature, consumers' brand attitude towards brand can be highly predictive to brand preference. As a result, brand preference can also belong to attitudinal category, while brand attachment obviously belongs to relational category.

\section{2) Related-behavior}

Brand preference is not something derived directly from intrinsic logics embedded in brain but from various situational variables. Indeed, consumers' brand preference can be the result of calculating gain-and-loss depending on their specific purposes. As a result, brand preference is very likely to be constructed. By contrast, brand attachment represents the relationship between consumers and brands, which stands for a relative stability in a given period.

\section{E. Attachment VS Trust}

Park et al (2006) note that the formation of brand attachment can be based on various resources that brands provide to consumers. In addition to resources, there is an important premise for consumers' attachment to brands. That is trust. Hiscock (2001) notes that the ultimate goal of marketing is to form an strong bond between brands and consumers and trust is essential to this bond. According to attachment theory, trust can be conceptualized as security in psychology. Conversely, in marketing region, trust can be conceptualized as security that consumers psychologically perceive from brands.

All in all, brand trust is the premise for consumers' emotional attachment to brands. In other words, brand attachment intrinsically includes consumers' trust to brands, which resonates with findings in psychology: an individual derives sense of security from the attachment figure.

\section{F. Attachment VS Satisfaction}

\section{1) Brand-self connection}

Brand satisfaction is based on consumers' subjective evaluation that whether brand performance reach or exceed their exceptions or not. From this perspective, these two constructs bear some similarity. Brand attachment also is based on consumers' subjective judgment. However, brand attachment is the comparison between brands' philosophy and consumers' self-concept.

\section{2) Related-behavior}

Consumers can feel satisfaction as soon as they consume brands. However, brand attachment is a result of long-term interaction between consumers and brands. Brand attachment comes along with explicit behavior output, such as proximity maintenance and separation distress, whereas brand satisfaction is less probable to have these behavior cues. 
Moreover, brand satisfaction is also an essential element to consumers' brand attachment. In other words, brand attachment contains consumers' general satisfaction to brands.

\section{G. Attachment VS Love}

Brand love is a relative new term coined by Carrol and Ahuvia (2006), which means consumers' emotional attachment to satisfied brands. Many consumers expressed their emotional attachment to loved brands. So emotional attachment to brands can embody brand love but not limited to it. Researchers have identified different love, such as maternal love, romantic love and sexual love, which can also be embodied by emotional attachment. We can say that emotional attachment to brands is a tag labeling consumers' love to brands. According to Carrol and Ahuvia, brand love contains passion and attachment to brands, positive evaluation and emotion to brands and love pledge. We argue that attachment is the core of all these brandrelated reactions,because: 1)attachment makes brands internalized as a part of self-concept; 2) other brand-related reactions can be derived from emotional attachment to brands.

\section{H. Attachment VS Loyalty}

Lots of measures to brand loyalty is just based on consumers' purchase behavior, such as exclusive purchase, most frequent purchase and prior purchase. This kind of measurement has been exposed to critics for a long time. Only we guarantee that consumers' repurchase behavior is intentional, we can call it true brand loyalty which requires consumers' positive and differential attitude towards the brands. However, it seems effective for marketing practitioners to assess consumers' loyalty only based on behavior. We find interesting definitions from American Marketing Association(AMA) dictionary about brand loyalty, which are totally based on consumers' behavior. In this way, there is no necessity to compare loyalty with attachment which mainly depicts consumers' psychological status.

\section{Hierarchical relation among these similar constructs}

We find that these similar constructs representing consumers' different reactions to brands exist a hierarchical relation. The process from brand involvement to brand attachment hints the development of consumers' cognition and emotion with brands and can be concluded into three phases briefly: A)being familiar with brands; B)being acquainted with brands and $\mathrm{C}$ )being in love with brands.

\section{A. Being familiar with brands}

In the first phase, consumers meet with brands in marketplace. With gradual interaction with brands, consumers can form general attitude towards brands. Theoretically, attitude can be changed by two major ways: 1)central route, characterized by high degree process of brand information which always comes along with high involvement; 2)peripheral route, characterized by low degree process of brand information but being sensitive to situational or contextual cues, which always comes along with low involvement. If consumers consider that brands attribute is important to themselves, they will pay more attention to brand information and process it in a higher degree and vice versa.

\section{B. Being acquainted with brands}

In the second phase, brands become consumers' trusted acquaintance. Consumers will form positive brand attitude towards brands which have satisfied them. As positive attitudes accumulate in consumers' mind, consumers to some extent will show relatively unstable brand preference. In further interaction, consumers will become acquainted with brands and trust them if the feedback from brands keeps positive. From brand satisfaction to trust is a process from quantity to quality. Brand trust provides an essential element for relationship between consumers and brands. Absence of trust will expose consumers to uncertainty and risk. Hence, consumers will not make their commitment to brands. All in all, no trust no attachment.

\section{Being in love with brands}

On the basis of brand trust, consumers' psychological and behavioral inclination will get stabilized in further interaction. As a result, consumers will show explicit brand preference and stable brand commitment. According to different motives to brand preference and commitment, there will develop two subbranches here. The first branch is mainly based on cognition. Consumers's brand preference and commitment is mainly the result of calculating gain-and-loss. And consumers will show some loyal behavior, such as repurchase, postponing purchase plan when brand is temporally unavailable. The second brand is mainly based on affection. Consumers' brand preference and commitment is mainly the result of emotional resonance. And consumers will show some desiring behavior for practitioners, such as relatively insensitive to price, ignoring competitors' brands and actively engaging in brand community. Conclusively, the main difference between the two branches is the degree of emotional investment.

\section{General discussion and future research}

In marketing context, it is an essential subject to understand and predict consumers' reactions to brands. In this research, we aim at brand attachment and make a comprehensive comparison with similar constructs. During the comparison, we find something interesting. That is, these similar constructs representing consumers' different reactions to brands exist a hierarchical relation where brand attachment is at the top and extremely related to brand equity.

At the same time, some questions have aroused correspondingly. The first: this hierarchical relation is theoretically plausible but not validated empirically. The second: in marketing context, there is no unifying guidelines for companies to penetrate brands philosophy into consumers' own self-concept. The third: if emotion is added to brand loyalty, there will be no significant difference between brand attachment and brand loyalty. So is that viable if we regard brand attachment as a form of brand loyalty? 


\section{Acknowledgment}

This paper is supported by Program of "Xinmiao" Talents in Zhejiang Province (Project No. 2012R406008).

\section{Reference}

[1] American Marketing Association Dictionary. Retrieve date: 2013-4-29. http://www.marketingpower.com/_layouts/Dictionary.aspx?dLetter=B\# brand+loyalty.

[2] Amine A. 1998. Consumers' true brand loyalty: the central role of commitment. Journal of Strategic Marketing, 6(4):305-319.

[3] Belk R W. 1988. Possessions and the extended self. Journal of Consumer Research, 15(1):139-168.

[4] Carrol B A, Ahuvia A C. 2006. Some antecedents and outcomes of brand love. Marketing Letters, 17(2):79-89.

[5] Cohen J B, Reed M. 2006. A multiple pathway anchoring and adjustment (MPAA) model of attitude generation and recruitment. Journal of Consumer research, 33(1):1-15.

[6] Delgado-Ballester E, Munuera-Aleman J L, Yague-Guillen M J. 2003. Development and validation of a brand trust scale. International Journal of Market Research, 45(1):35-54.

[7] Fournier S. 1998. Consumers and their brands: Developing relationship theory in consumer research. Journal of Consumer Research, 24(4):343373
[8] Grisaffe D B, Nguyen H P. 2011. Antecedents of emotional attachment to brands. Journal of Business Research, 64(10):1052-1059.

[9] Hazan C, Shaver P R. 1994 . Attachment as an organizational framework for research on close relationships. Psychological inquiry, $5(1): 1-22$.

[10] Olson E L, Thjømøe H M. 2003. The effects of peripheral exposure to information on brand preference. European Journal of Marketing, 37(1/2):243-255.

[11] Park C W, MacInnis D J, Priester J. 2006a. Brand attachment: Constructs, consequences and causes. Foundations and Trends in Marketing, 1(3):191-230.

[12] Park C W, MacInnis D J, Priester J. 2006b. Beyond attitudes: Attachment and consumer behavior. Seoul National Journal, 12(2):3-36.

[13] Park C W, Young S M. 1986. Consumer response to television commercials: The impact of involvement and background music on brand attitude formation. Journal of Marketing Research, 23(1):11-24.

[14] Thomson M, MacInnis D J, Park C W. 2005. The ties that bind: Measuring the strength of consumers' emotional attachments to brands. Journal of Consumer Psychology, 15(1):77-91.

[15] Wang J, Lee A Y. 2006. The role of regulatory focus in preference construction. Journal of Marketing Research, 43(1):28-38.

[16] Zaichkowsky J L. 1985 .Measuring the involvement construct. Journal of Consumer Research, 12(3):341-352. 